\title{
Remote Lab for Robotics Applications
}

\author{
https://doi.org/10.3991/ijoe.v14i01.7674 \\ Robinson Jiménez M. ${ }^{(凶)}$, Oscar F. Avilés S, Mauricio F. Mauledoux M. \\ Nueva Granada Military University, Bogotá, Colombia \\ robinson.jimenez@unimilitar.edu.co
}

\begin{abstract}
This article describes the development of a remote lab environment used to test and training sessions for robotics tasks. This environment is made up of the components and devices based on two robotic arms, a network link, Arduino card and Arduino shield for Ethernet, as well as an IP camera. The remote laboratory is implemented to perform remote control of the robotic arms with visual feedback by camera, of the robots actions, where, with a group of test users, it was possible to obtain performance ranges in tasks of telecontrol of up to $92 \%$.
\end{abstract}

Keywords—remote environment, remote lab, robotic arm, robotics training

\section{$1 \quad$ Introduction}

With the increasing boom of robotics in all human activities, being familiar with the control of a robotic agent is not unusual. Robotic toys today are very common, it is possible to find from assistive robots to support feeding to people with limitations [1] to assistant robots of physical activity for adolescents [2], which are part of the great variety of developments found in the state of the art. The presentations of the robotic agents are very varied, until reaching critical support points, as intermediaries in teleoperations [3]. This type of applications allows to see the incidence of the robots in the activities of the man and his improvement of the quality of life.

Due to this, to develop platforms of training in the control of robots, versatile for any age range, becomes important for its assertive use and development. Nowadays, with the possibility of remote control of different systems, such as air conditioning [4], control of robots [5] and similar, coupled with the advantages of virtual laboratories [6], remote laboratories for telecontrol robots offer solutions for needs such as training in various areas [7], for example in the case of teleoperation.

Remote laboratory environments already carry several developments reported in the state of the art [8][9], and have shown several advantages, such as low cost implementation [10][11] and skill development in robot control and programming algorithms [12][13]. In this article, it is presented a remote laboratory environment for telecontrol of two robotic arm type agents, capable of interacting with each other, using visual feedback from the user through an IP camera, looking for a simple environment of easy assimilation, for learning and training in robot telecontrol. 
Then the article is divided into 4 sections, section two describes the design of the remote laboratory, section three presents the analysis of results and finally section four gives the conclusions reached.

\section{Application environment}

The proposed remote laboratory consists of the manipulation of two robotic arms to tele-command, a monitoring camera for visual feedback and an Arduino card with expander card for Ethernet connectivity, network access routers are used to connect the remote site with the laboratory. In the remote site there is a web interface for manipulation of each degree of freedom by robotic agent and setting of the connection. This scheme, which proposes a bidirectional communication, is shown in figure 1.
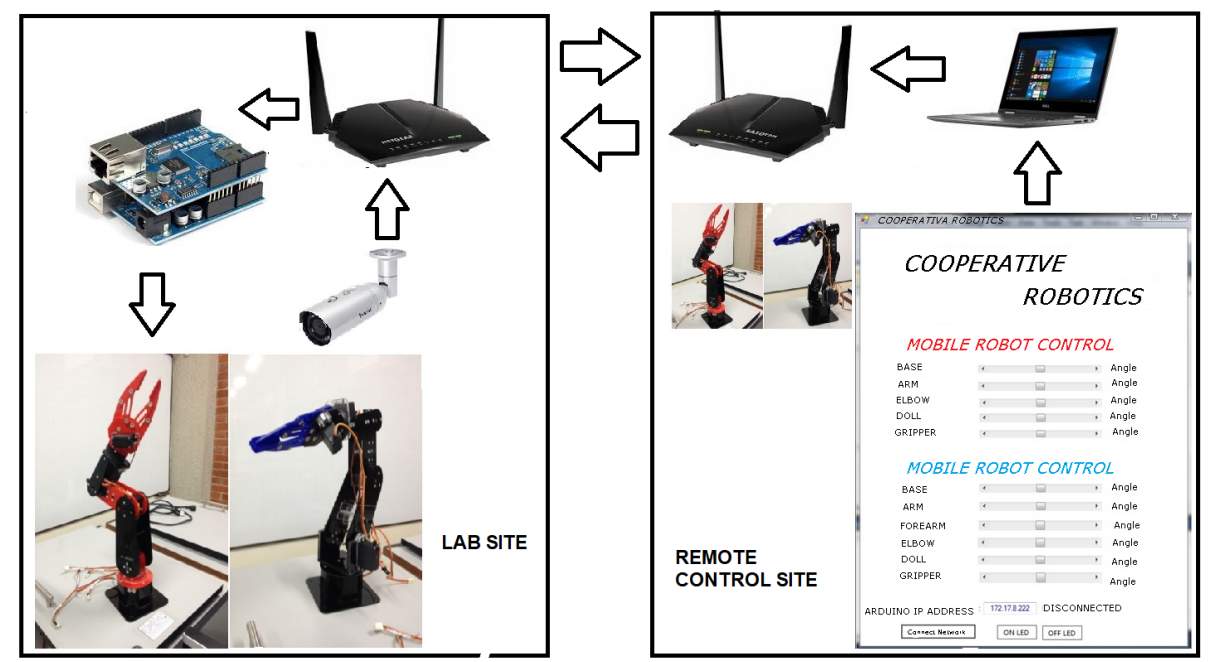

Fig. 1. Application environment.

The first aspect required is to do the kinematic analysis of the robot with respect to a reference system, which allows to determine the position and orientation of the end effector of the robot, known the values of the joints and the geometric parameters of the elements of the robot. For this analysis the Denavit-Hartenberg (D-H) algorithm is used, which is based on the assignment of axes coordinated by degrees of freedom as shown in Figure 1, both robotic arms used have the same architecture.

The kinematic analysis, as shown in figure 2, is derived to determine the D-H matrix, which allows to relate the spatial variations of each degree of freedom and to concatenate them. The virtual environment will allow manipulating each degree of freedom, for the rotational case, using the D-H matrix shown in Table 1. 


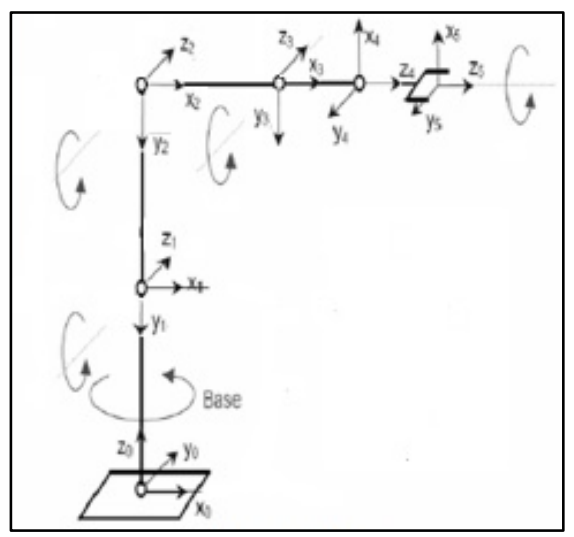

Fig. 2. Inverse Kinematics.

Table 1. Kinematic matrix

\begin{tabular}{|c|c|c|c|c|}
\hline Joint & $\boldsymbol{\theta}$ & $\mathbf{d}$ & $\mathbf{a}$ & $\boldsymbol{\alpha}$ \\
\hline 1 & $\mathrm{q} 1$ & $\mathrm{~d} 1$ & 0 & -90 \\
\hline 2 & $\mathrm{q} 2$ & 0 & $\mathrm{~d} 2$ & 0 \\
\hline 3 & $\mathrm{q} 3$ & 0 & $\mathrm{~d} 3$ & 0 \\
\hline 4 & $\mathrm{q} 4-90$ & 0 & $\mathrm{~d} 4$ & -90 \\
\hline 5 & $\mathrm{q} 5$ & $\mathrm{~d} 5$ & 0 & 0 \\
\hline
\end{tabular}

The energization of all degree of freedom, controlled by servomotor, requires a regulated source of 12 volts at a current of 5 amperes, for the adequate manipulation of both arms, in total 12 servomotors, the power supply provides 12 volts and a maximum current of 5 amps. A voltage regulator L78S05 is used for supplying the Arduino board which regulates the pulse modulation signal of each servomotor and the Ethernet connectivity card used, Figure 3 illustrates the connection circuit designed for the integration of the source to the Arduino control board and servomotors connections of each arm.
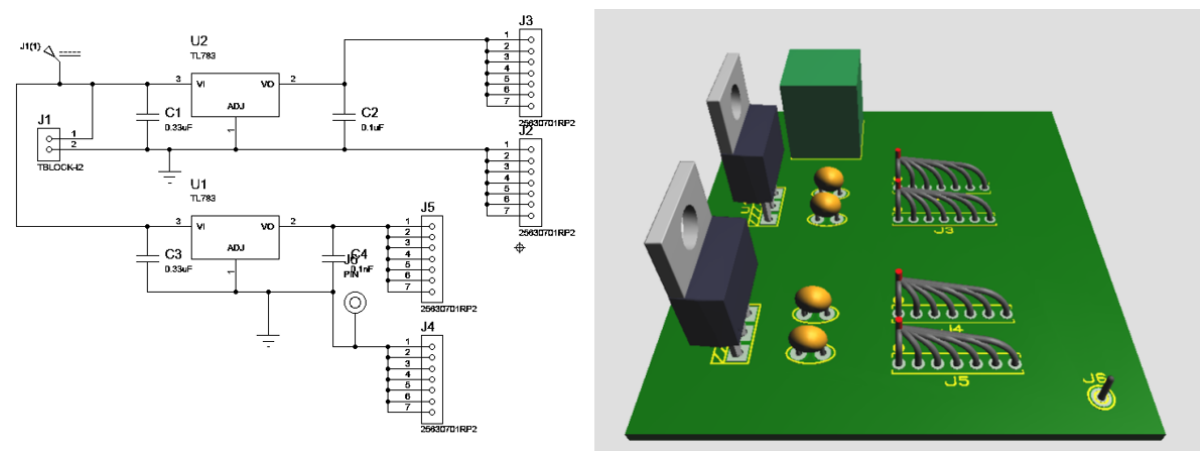

Fig. 3. Control circuit. 
Figure 4 illustrates the implementation of the circuit and Arduino cards used, in the area of the physical laboratory.

Figure 5 shows the robotic command interface of each of the degrees of freedom per arm, which is located on the remote computer. For visual association of the user two colors are used, red for arm one and blue for arm two. Shift bars are used for greater agility in the variation of movement of the robotic arm, towards the left side the angle decreases and towards the right it increases. The interface includes the field of assignment of the IP address of the Arduino card in the remote area to be reached by the Ethernet network. On the left side the visual feedback part is visible to the user via the IP camera, the interface allows the IP address to be entered. The environment of this application was implemented in $\mathrm{C}$ language under the Visual Studio software.

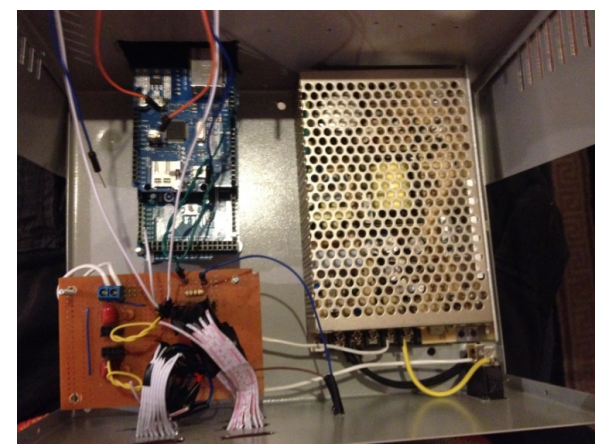

Fig. 4. Integration of circuits for robotic control.

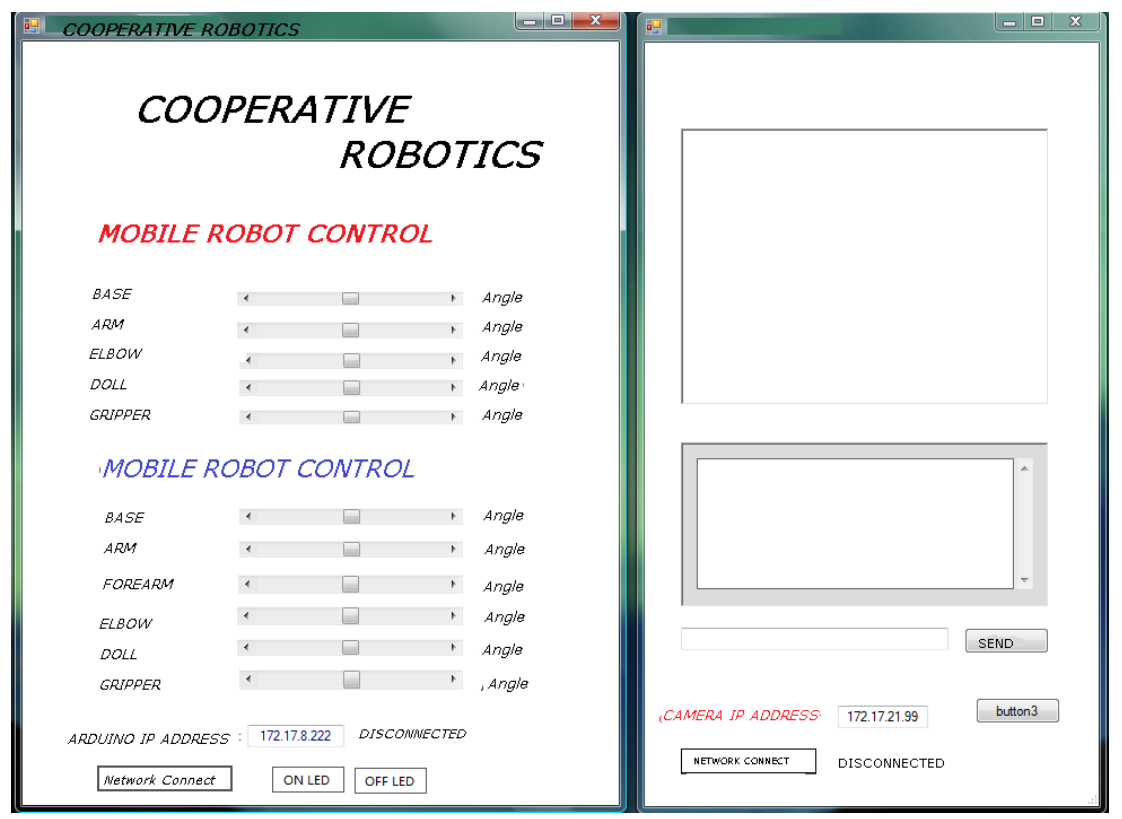

Fig. 5. Remote monitoring and control tool 
Figure 6 shows a flow diagram that guides the start-up logic of the remote application. It must be initialized by doing the network connection, once done, it will initiate the transfer of information from the remote application to the Arduino in the lab and from the IP camera in the lab to the remote interface.
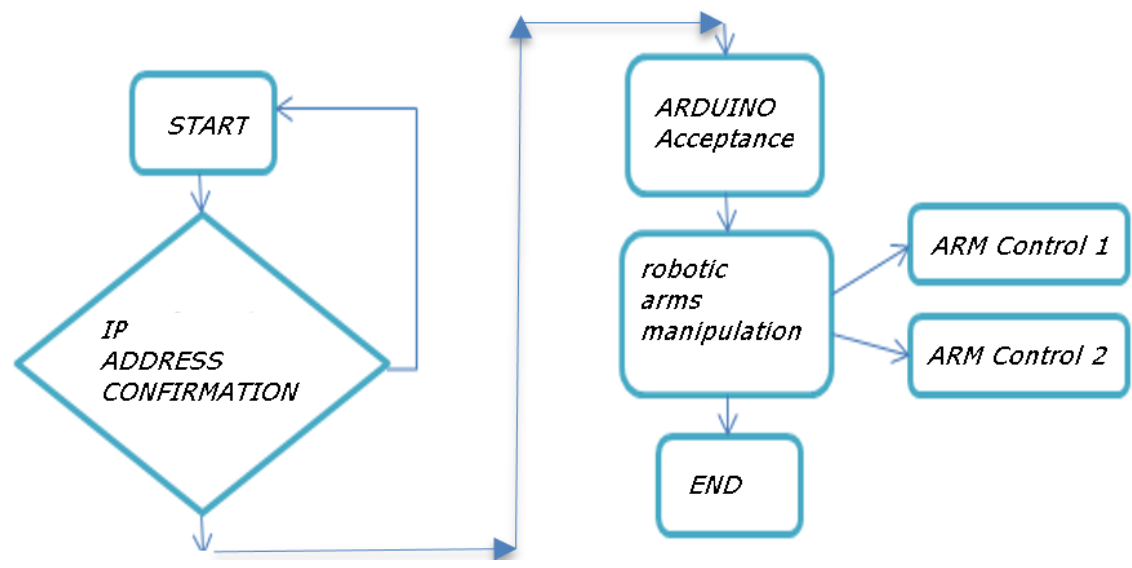

Fig. 6. Flow diagram of operation.

\section{Results}

To evaluate the remote working environment, a sequence of manipulation of the robotic arms is done to perform a joint object grab task, this sequence consists in manipulating the red robotic arm to pick up a didactic ball, take it to the end effector of the blue robotic arm and it must grab it and move it to another location. Figure 7 illustrates the set sequence, for the case by 5 different users.

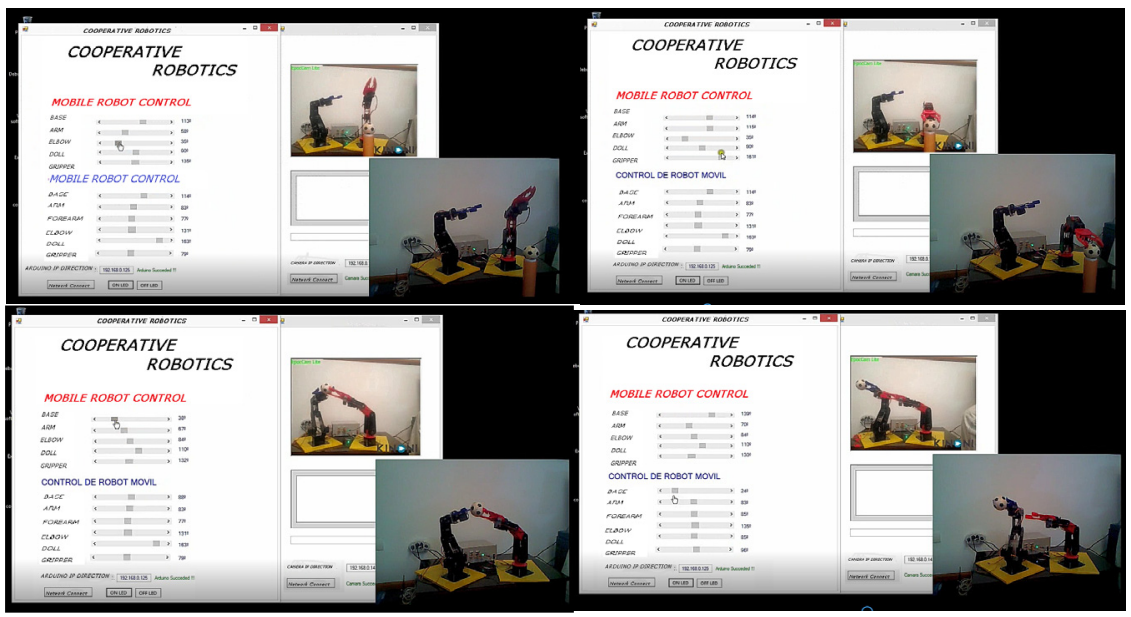

Fig. 7. Test sequence. 
Table 2 lists the results obtained when performing the sequence to the test users, who were previously trained in the manipulation of the different degrees of freedom, so that they had a certain level of familiarity with the remote environment and the control of the robot. Accuracy is determined by tolerance values established as metrics in the execution of movements, for example, taking the ball properly and delivering it, without falling during the process, without exceeding the end position of the desired end point, i.e. having to return to reposition some degree of freedom, etc.

Table 2. User Validations

\begin{tabular}{|l|c|c|c|c|c|}
\hline \multicolumn{1}{|c|}{ Test } & $\mathbf{1}$ & $\mathbf{2}$ & $\mathbf{3}$ & $\mathbf{4}$ & $\mathbf{5}$ \\
\hline Accuracy (\%) & 92 & 88 & 82 & 78 & 89 \\
\hline Time (min) & 3,57 & 4,12 & 4,46 & 4,51 & 4,38 \\
\hline
\end{tabular}

From the results it can be observed that the task is performed by all users and, according to the expertise of each one, it requires more or less execution time. Subjective factors such as caution are introduced, which at the time characterized the user 5 that with a precision of $89 \%$ handled the controls of each robot more carefully to avoid passing a visual reference of displacement, according to the feedback of the camera, which is why it took much longer, compared with user 2 , who operated the robots with almost the same precision.

There are some variations of latency in the communication with the IP camera, due to the amount of information to be transmitted, proper to the video signal. These were controlled by an iterative adjustment of the image capture resolution so that it would not be unnecessarily reduced beyond the value according to a time delay noticeable by sight.

\section{Conclusions}

A remote environment was designed for telecontrol of robotic agents, allowing the proper manipulation of two robotic arms distant through network links. Because of the design features, the remote platform is generic to the kind of user that can operate it, given its simplicity. This design makes the platform functional to students of secondary or professional education.

With this virtual environment it can be developed and verified pre-program routines to the offline mode manipulator, facilitating the user the learning process in telecontrol practices. Although kinematics is involved in the development of the control algorithm for each degree of freedom, including the spatial reference of the effector point to an object of interest would allow better metrics to be performed in precision tasks.

This type of environment allows a simple and inexpensive robotic telecontrol learning interface, usable from anywhere with network connection, easily adaptable to any type of robotic action sequence, such as telesurgery. 


\section{$5 \quad$ References}

[1] M. Guo, P. Shi and H. Yu, "Development a feeding assistive robot for eating assist," 2017 2nd Asia-Pacific Conference on Intelligent Robot Systems (ACIRS), Wuhan, 2017, pp. 299-304. https://doi.org/10.1109/ACIRS.2017.7986112

[2] K. Swift-Spong, C. K. F. Wen, D. Spruijt-Metz and M. J. Matarić, "Comparing backstories of a Socially Assistive Robot exercise buddy for adolescent youth," 2016 25th IEEE International Symposium on Robot and Human Interactive Communication (RO-MAN), New York, NY, 2016, pp. 1013-1018. https://doi.org/10.1109/ROMAN.2016.7745233

[3] M. Bowthorpe, M. Tavakoli, H. Becher and R. Howe, "Smith Predictor-Based Robot Control for Ultrasound-Guided Teleoperated Beating-Heart Surgery," in IEEE Journal of Biomedical and Health Informatics, vol. 18, no. 1, pp. 157-166, Jan. 2014. https://doi.org/10.1109/JBHI.2013.2267494

[4] He, Y. and Tan, M. (2017). Implementation of Air-conditioning Control Technology Based on Wireless Sensor. International Journal of Online Engineering (iJOE), 13(07), p.91. https://doi.org/10.3991/ijoe.v13i07.7287

[5] An, P. (2017). An Algorithm of Mobile Robot Node Location Based on Wireless Sensor Network. International Journal of Online Engineering (iJOE), 13(05), p.4. https://doi.org/10.3991/ijoe.v13i05.7044

[6] Aşıksoy, G. and Islek, D. (2017). The Impact of the Virtual Laboratory on Students' Attitude in a General Physics Laboratory. International Journal of Online Engineering (iJOE), 13(04), p.20. https://doi.org/10.3991/ijoe.v13i04.6811

[7] Gabriele, L., Marocco, D., Bertacchini, F., Pantano, P. and Bilotta, E. (2017). An Educational Robotics Lab to Investigate Cognitive Strategies and to Foster Learning in an Arts and Humanities Course Degree. International Journal of Online Engineering (iJOE), 13(04), p.7. https://doi.org/10.3991/ijoe.v13i04.6962

[8] S. Nayak, P. Vakrani, A. Purohit and G. N. S. Prasanna, "Remote Triggered Lab for Robotics: Architecture, Design and Implementation Challenges," 2014 IEEE Sixth International Conference on Technology for Education, Clappana, 2014, pp. 214-217. https://doi.org/10.1109/T4E.2014.24

[9] I. Angulo et al., "RoboBlock: A remote lab for robotics and visual programming," 2017 4th Experiment@International Conference (exp.at'17), Faro, 2017, pp. 109-110. https://doi.org/10.1109/EXPAT.2017.7984373

[10] L. Tobarra et al., "Low-cost remote laboratories for renewable energy in distance education," 2014 11th International Conference on Remote Engineering and Virtual Instrumentation (REV), Porto, 2014, pp. 106-111. https://doi.org/10.1109/REV.2014.6784235

[11] R. Radhamani, N. Nizar, D. Kumar, B. Nair, K. Achuthan and S. Diwakar, "Low cost neuro-inspired robots for sustainable laboratory education," 2016 International Conference on Robotics and Automation for Humanitarian Applications (RAHA), Kollam, 2016, pp. 1-6. https://doi.org/10.1109/RAHA.2016.7931870

[12] M. Casini, D. Prattichizzo and A. Vicino, "A student control competition through a remote robotics lab," in IEEE Control Systems, vol. 25, no. 1, pp. 56-59, Feb. 2005. https://doi.org/10.1109/MCS.2005.1388802

[13] S. Kodagoda, A. Alempijevic, S. Huang, M. de la Villefromoy, M. Diponio and L. Cogar, "Moving away from simulations: Innovative assessment of Mechatronic subjects using remote laboratories," 2013 12th International Conference on Information Technology Based Higher Education and Training (ITHET), Antalya, 2013, pp. 1-5. https://doi.org/10.1109/ITHET.2013.6671051 


\section{Authors}

Oscar F. Avilés S. was born in Bogotá, Colombia, in 1967. He received the Engineer degree in Electronics and Specialization in Electronic Instrumentation from the Antonio Nariño University - UAN - in 1995 and 2002, respectively. Master in Automatic Production Systems - Technological University of Pereira - 2006 Colombia and Ph.D. in Mechanical Engineering in Campinas State University - UNICAMP - Brazil. Currently he is Professor in the Department of Mechatronics Engineering in Nueva Granada Military University - UMNG. He has experience in the areas of Electronic Engineering, with emphasis on electronic instrumentation and control systems, acting mainly on the following topics: robotics, control and biomechatronics.

Robinson Jiménez Moreno was born in Bogotá, Colombia, in 1978. He received the Engineer degree in Electronics from the Francisco José de Caldas district University - UD - in 2002, respectively. Master in Industrial Automation from the Universidad Nacional de Colombia - 2012 and third year PhD student in Engineering of the Francisco José de Caldas district University - UD. He is currently an Assistant Professor in the Mechatronics Engineering Program of the Nueva Granada Military University - UMNG. He has experience in the areas of Instrumentation and Electronic Control, acting mainly in: Robotics, Control, pattern recognition and image processing.

Mauricio F. Mauledoux M. was born in Bogotá, Colombia, in 1982. He received the Engineer degree in Mechatronic engineering from the Nueva Granada Military University, in 2005. In 2008 as a student of the Master in Information Technologies and Intelligent Systems in the St. Petersburg State Polytechnic University, Russia, at the automatic and intelligent distributed control department, he was promoted to a Ph.D. In 2011 He received the Ph.D. degree in Mathematical models, numerical methods and software systems (Red Diploma) from the St. Petersburg State Polytechnic University, Russia. In 2012, he joined the Department of Mechatronic Engineering, at Nueva Granada Military University, in Colombia, as an Assistant Professor. His current research interests include Robotics, automatic control, Multi-agent Systems, Smart Grids, and Optimization.

Article submitted 06 September 2017. Published as resubmitted by the authors 13 November 2017 